\title{
An Improved MPPT Algorithm to Minimize Transient and Steady State Oscillation Conditions for Small SPV Systems
}

\author{
Kashif Javed, Haroon Ashfaq* and Rajveer Singh
}

Department of Electrical Engineering, Jamia Millia Islamia, New Delhi, India

\begin{abstract}
Small solar PV systems mostly residential PV systems are bounded to be low cost. So these systems are required low-cost processors, and these low-cost processors can only process simple algorithm efficiently. The conventional P\&O MPPT algorithm is widely employed algorithm to control solar PV systems because of its simplicity, low cost, and ease of implementation. During rapid radiation change condition (RRC) the output voltage of conventional P\&O MPPT algorithm is found unstable and suffers oscillations around MPP at transient and steady state conditions. This paper proposes a simple MPPT algorithm for small or residential solar PV systems to eliminate such above said drawbacks. The proposed MPPT controls the step size (dD) of the boost converter duty cycle (D) according to the system input conditions and have the ability to compensate the transient as well as steady-state oscillations around MPP and stabilize the output voltage under RRC and variable load conditions. To validate the proposed algorithm, a $1 \mathrm{~kW}$ photovoltaic system model is simulated using MATLAB/Simulink, and the performance of the system is also investigated under RRC. The performance of proposed MPPT algorithm is found to be adequate under various insolation patterns. An experimental set-up comprising a boost converter, solar emulator with dSPACE controller is also used to investigate the performance of proposed MPPT algorithm further.
\end{abstract}

Keywords: Solar PV, MPPT, Transient State Oscillations, Steady State Oscillations.

Article History: Received October $4^{\text {th }}$ 2017; Received in revised form September 15 ${ }^{\text {th }}$ 2018; Accepted November 1st 2018; Available online How to Cite This Article: Javed, K., Ashfaq, H and Singh, R. (2018). An Improved MPPT Algorithm to Minimize Transient and Steady State Oscillation Conditions for Small SPV Systems. International Journal of Renewable Energy Development, 7(3), 191-197.

https://doi.org/10.14710/ijred.7.3.191-197

\section{Introduction}

Solar energy is the most popular source of energy among all renewable energy resources (Bangyin et al. 2011). Solar photovoltaic (PV) systems are environment-friendly, less costly and require low maintenance (Li et al. 2011 and Agorreta et al. 2011) The solar photovoltaic grid-connected systems are presently commercialized due to ease of installation process and long module life (Young-Hyok et al. 2011). Every solar PV system uses a control algorithm, called maximum power point tracking (MPPT) algorithm to track maximum power point (MPP) (Bo et al. 2010). The MPPT ensures that the photovoltaic system always generates maximum power under varying environmental (radiation \& temperature) conditions (Serban et al. 2010). The efficiency of the photovoltaic system also depends on the MPPT algorithm, simpler the algorithm lesser the implementation time; hence, faster the tracking speed. An MPPT technique senses photovoltaic module voltage and current and controls the boost converter duty cycle to track MPP. Researchers developed many MPPT techniques to track MPP with improved efficiency and tracking speed are present in the literature (Fatahbadi et al. 2017, Athira et al. 2016, Abdelsalam et al. 2011, and Mutoh et al. 2006). Most of these methods generally calculate the ratio of the PV voltage and current and intern controls the boost converter duty cycle to track the MPP. The accuracy of these algorithms is found marginal and the tracked power may be below the maximum power which results in power loss (Faranda et al.2008, Esram et al. 2007, Hua et al. 1998, Hohm et al. 2000, Hussein et al. 1995, and Sera et al. 2008).

The Perturb \& Observation (P\&O) method is a widely employed MPPT technique. Perturbation in PV voltage is done using the reference as present $\mathrm{PV}$ power $\mathrm{P}(\mathrm{K})$, and the past $\mathrm{PV}$ power $\mathrm{P}(\mathrm{K}-1)$ is taken as operating power. If the value of $\mathrm{P}(\mathrm{K})$ is greater than $\mathrm{P}(\mathrm{K}-1)$, then the track of perturbation is continued accordingly, otherwise, it reversed (Abdelsalam et al. 2011. Although this algorithm is simple but under steady state condition, high oscillations are found around MPP. The performance of the P\&O MPPT technique is dependent on the trade-off between tracking of speed and oscillations around MPP (Masoum et al. 2002). On reducing the perturbation value, the oscillations are reduced, but the system goes slow and vice-versa. During the rapid change of irradiation the algorithm loses its direction and unable to track the actual MPP (Femia et al. 2005). Under some special conditions like the partial shading on PV modules, this technique often fails to track the maximum power point (MPP) due to multiple peaks in the P-V curve, and MPPT algorithm is not able to recognize the global peak among local peaks (Patel et al. 2008).

On the other hand, another popular MPPT, i.e. incremental conductance (IC) technique has a quality not

\footnotetext{
* Corresponding author: harun_ash@yahoo.com
} 
to lose the tracking direction, but it suffers from oscillation and speed problems as that of $\mathrm{P} \& \mathrm{O}$ technique. There are various improved IC techniques available in the literature having the same trouble (Safari et al. 2011, Yan et al. 2008, Liu et al. 2007, Liu, et al 2008, Mei, et al. 2011, Tey et al. 2014, Tey et al. 2014, and Safari et al. 2011). Lee et al. in (2006) tried to minimize the oscillations at MPP, but during a random change in radiation, the tracking speed of MPPT goes down which results in loss of power.

The converter duty cycle control is another widely used method to track MPP of the solar photovoltaic system. Hill climbing (HC) or direct control technique uses duty cycle control to track MPP is also available in the literature. It works similarly as $\mathrm{P} \& \mathrm{O}$ technique except it continuously revises the operating point of the power by perturbing the duty cycle of converter instead of perturbing of voltage or current (Lee et al. 2006, Xiao et al. 2004, and Xiao et al. 2004). However, the same problems as that in $\mathrm{P} \& \mathrm{O}$ and IC technique are reported.

Some artificial intelligence (fuzzy-logic and neural network) based control approaches are also available in the literature to tackle the oscillating problem around MPP (Alajmi et al. 2011 and Rai et al. 2011). These MPPT techniques are quite successful in compensating the nonlinear characteristics of I-V curves. The fuzzy-logic based system consists of fuzzification, defuzzification, inference mechanism and storage subsystems. Neural network based systems also require a large amount of data to train the system. Thus, these MPPT techniques are very complex and cannot be implemented using low or medium cost processors.

Some evolutionary Algorithms (EA) are inspired by nature has been used by researchers to develop MPPT techniques for solar PV system, are also found in the literature. The beauty of evolutionary algorithm techniques is that it can handle nonlinear objective functions. There are many EA techniques reported in literature like PSO, GA, and ACO that can be used to track MPP. Although these MPPT techniques are accurate but are not easy to implement due to high-performance processing system requirements. The power tracking speed of PSO based MPPT technique seems to be low because it takes time to search the particles. Due to this, the PSO based MPPT technique has a large steady state power loss.

The small or residential low cost PV systems do not have high performance processors to implement all the above-said MPPT techniques. The processor used in these types of systems does not have high processing speed. High performing processing units increase the PV system cost, but small or residential PV systems are bounded to be affordable for middle-class consumers. So there is a need for a new simple and fast MPPT technique which can easily implement in small or residential PV systems, compensate steady state oscillations around MPP and stabilize the output PV voltage during RRC condition efficiently.

Here, a modified P\&O MPPT (MP\&O) algorithm is proposed which eliminates most of the drawbacks of conventional MPPT techniques. The proposed MP\&O MPPT works on control of step size (dD) of the duty cycle of the boost converter. The speed and accuracy of the MPPT technique depend on step size (dD). Larger the step size lesser the accuracy but the MPPT response is fast, and vice versa and the step size (dD) is fixed $\left(10^{-1}\right.$ to $\left.10^{-6}\right)$ in simple P\&O MPPT algorithm (Noguchi et al. 2002 and Ishaque et al. 2011). This new MP\&O algorithm varies the step size (dD) according to input radiation and load conditions. The stability of output voltage during RRC condition and compensation of oscillations at MPP is the major advantage of proposed MPPT algorithm over conventional control algorithms during constant or non-fluctuating radiation conditions.

The performance of both (P\&O and Modified MPPT) algorithms are evaluated under different radiation conditions. For test purposes, the input radiation data to the system has been considered from Ministry of New and Renewable Energy (MNRE) website (rredc.nrel.gov) for the location of New Delhi, India. This algorithm is implemented on a classical boost converter connected to a solar photovoltaic simulator. To validate the simulation results a dSPACE 1104 controller with a TMS320F240 digital signal processor is used to implement the algorithm.

The organization of this paper is as follows. The basic P\&O MPPT and proposed MP\&O MPPT technique is discussed in section II \& III. Description of PV system used and simulation with P\&O MPPT and proposed MPPT technique are available in detail in section IV. Simulation analysis of proposed MPPT technique under fluctuation and fast transient radiation condition is also discussed in this section. Section V comprises the experimental validation of proposed MPPT technique using the dSPACE controller.

\section{P\&O MPPT Technique}

As mentioned earlier in literature there are various MPPT techniques are proposed (Salas et al. 2006). Among them P\&O MPPT is most adopted technique to track MPP.

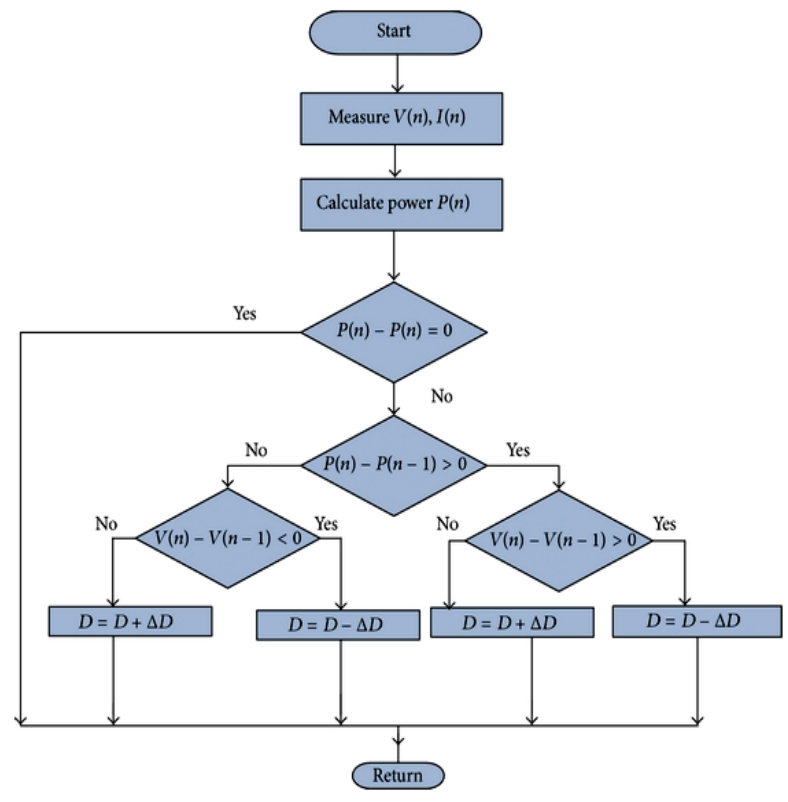

Fig. 1. P\&OMPPT Algorithm

The $\mathrm{P} \& \mathrm{O}$ algorithm increases or decreases the duty cycle by a step size called dD according to PV voltage and current value. At regular intervals of time, the comparison of PV output power with that of the previous value is done. If the PV voltage change increments the power, the control algorithm adjusts the operating point in that direction. Otherwise, the algorithm moves the operating point in the reverse direction. The algorithm continues to operate towards the maximum power point at each perturbation. 
This algorithm is very simple and easy to implement, but around steady state condition, the operating point vibrates across the maximum power point (MPP), and hence the output is oscillatory.

The P\&O MPPT technique uses fixed step size called $\mathrm{dD}$. The value of step size is responsible for the speed and accuracy of the photovoltaic system. Greater the step size lesser accuracy and vice versa. Settling time of the PV system is affected by the step size (dD) of the boost converter duty cycle. Larger step size decreases the settling time of the PV system and vice versa. However, the stability of the system also reduced.

\section{Modified P\&O MPPT (MP\&O) Algorithm}

The MP\&O MPPT technique eliminates the above said drawbacks of conventional P\&O MPPT technique, the flowchart of MP\&O MPPT algorithm is shown in Fig.2. This MPPT algorithm regulates the value of step size (dD) of boost converter duty cycle (D) according to the system input conditions. Initially, this algorithm reads the value of instantaneous radiation (Ir), photovoltaic voltage and current (V, I) and load power (P_Load) at every instant of time and calculates the differential value of these parameters. Radiation (Ir) and generated PV power is compared for accurate detection of RRC which helps to stabilize the output voltage. During constant radiation condition this algorithm makes the value of $\mathrm{dD}$ at its highest value which boost up the tracking speed of the MPPT algorithm. While on increasing/decreasing or RRC condition this algorithm feeds smallest value of $\mathrm{dD}$ to the boost converter which improves the tracking accuracy of MPPT algorithm.

In this, the duty cycle of the power converter is varied and updated periodically at every $\Delta \mathrm{T}$ time instant. The algorithm increases the duty cycle by a factor called $\mathrm{dD}$, when $\mathrm{P}(\mathrm{K})>\mathrm{P}(\mathrm{K}-1)$ and decreases with $\mathrm{P}(\mathrm{K})<\mathrm{P}(\mathrm{K}-1)$. This algorithm is expressed mathematically by the equation $1 \& 2$.

$\mathrm{D}(\mathrm{k})=\mathrm{D}(\mathrm{k}-1)+\mathrm{dD}(\mathrm{k})$, if $\mathrm{P}(\mathrm{k})>\mathrm{P}(\mathrm{k}-1)$

$\mathrm{D}(\mathrm{k})=\mathrm{D}(\mathrm{k}-1)-\mathrm{dD}(\mathrm{k})$, if $\mathrm{P}(\mathrm{k})<\mathrm{P}(\mathrm{k}-1)$

Where; $\mathrm{D}(\mathrm{k})$ is updated, and $\mathrm{D}(\mathrm{k}-1)$ is previous operating duty cycle of the boost converter. $\mathrm{dD}$ is the step size for change in duty cycle.

$d D(k)=\left\{\begin{array}{c}d D(k-1)+\mathrm{D}_{\mathrm{o}} \text { if } d I r<0, d I r \neq 0 \\ d D(k-1)-\mathrm{D}_{\mathrm{o}} \text { if } d I r>0, d P_{\text {Load }}<d P(k)\end{array}\right.$

$D(k)=\left\{\begin{array}{l}D(k-1)+d D(k) \text { if } d P>0, d V>0 \\ D(k-1)-d D(k) \text { if } d P>0, d V<0 \\ D(k-1)-d D(k) \text { if } d P<0, d V>0 \\ D(k-1)+d D(k) \text { if } d P<0, d V<0\end{array}\right.$

$\mathrm{dP}(\mathrm{k})=\{\mathrm{P}(\mathrm{k})-\mathrm{P}(\mathrm{k}-1)\} . \Delta \mathrm{T}$

$\mathrm{dP}_{\text {Load }}=\left\{\mathrm{P}_{\text {Load }(\mathrm{k})}-\mathrm{P}_{\text {Load }(\mathrm{k}-1)}\right\} \cdot \Delta \mathrm{T}$

Where: $\Delta \mathrm{T}$ is update time.

The step size and duty cycle of boost converter are illustrated in equation $3 \& 4$. The step size $\mathrm{dD}$ is being according to set of conditions based on change in irradiance and load power, this value is to calculate boost converter duty cycle (equation 4 ). The mathematical relation of duty cycle and step size contains all conditions related to irradiance (Ir), photovoltaic power (P) \& load power (P_Load). This technique is basically a search based tracking algorithm which updates the measured photovoltaic power $\mathrm{P}(\mathrm{k})$ and load power $\mathrm{P} \_$Load(k) at every instant of time as represents by equation $5 \& 6$.

\section{PV System Design \& Simulation Analysis}

\subsection{System description}

In this work, a $1 \mathrm{~kW}$ PV system is considered to investigate the performance of $\mathrm{P} \& \mathrm{O}$ and $\mathrm{MP} \& \mathrm{O}$ algorithm under different input radiation conditions.

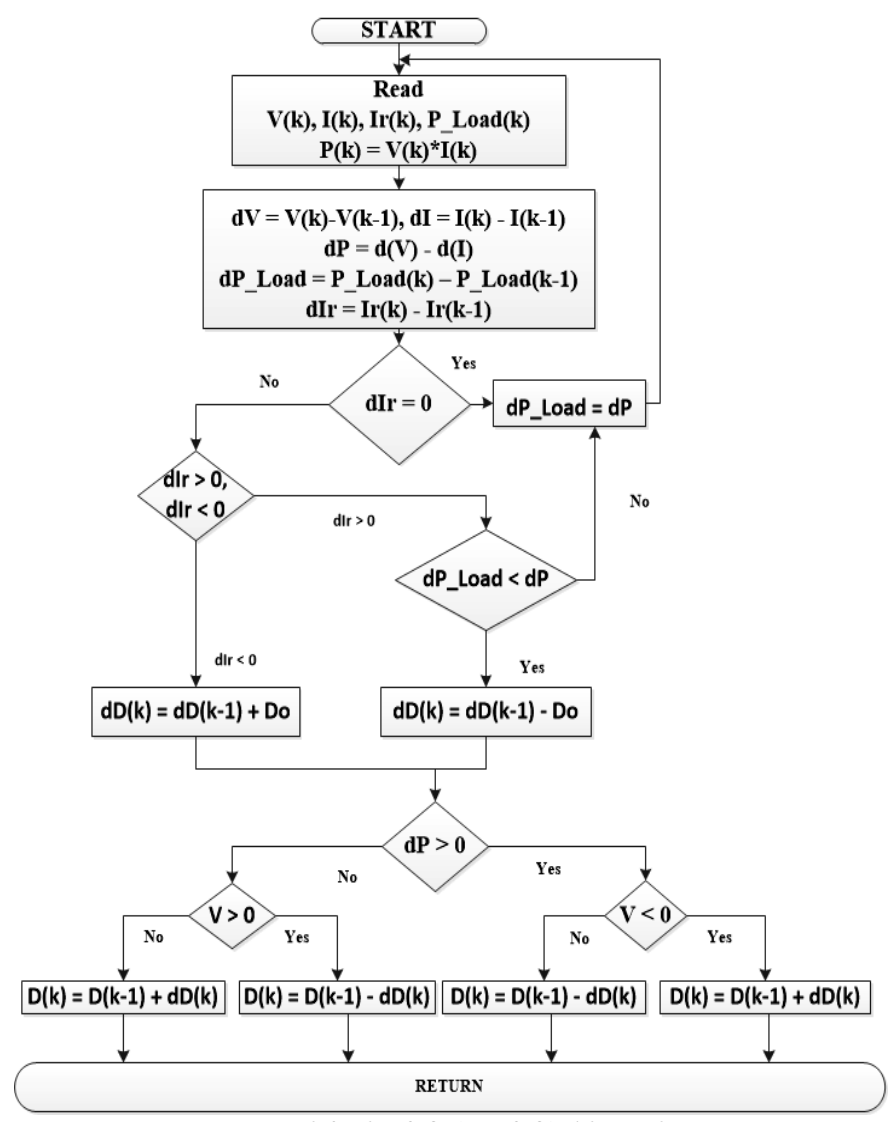

Fig.2. Modified P\&O (MP\&O) Algorithm

Table 1

Specification of PV Modules

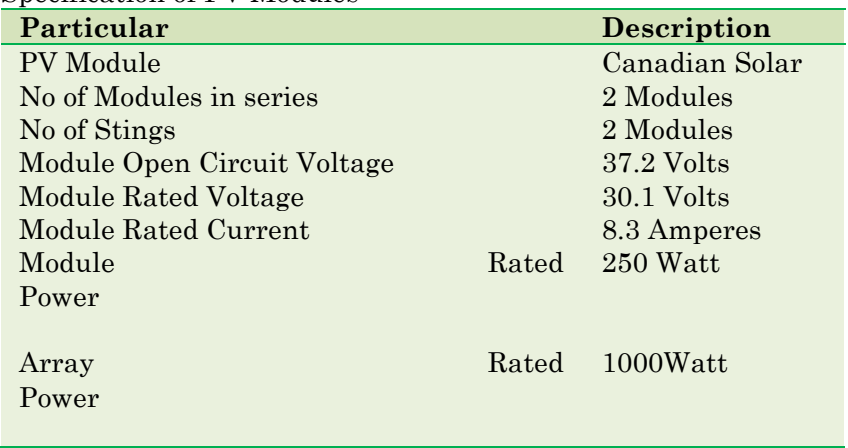

The configuration of proposed $\mathrm{PV}$ system with $\mathrm{P} \& \mathrm{O}$ and MP\&O MPPT algorithm are shown in Fig. 3. The simulated system has a PV array to produce solar power and an IGBT based 30-60V dc-dc boost converter to boost up PV voltage to a fixed $1 \mathrm{~kW}$ dc load. Canadian Solar 
CS6P-250PX solar module of $250 \mathrm{~W}$ rated power is used to formulate the PV array in MATLAB/Simulink simulation environment. The maximum power, current and voltage of this $\mathrm{PV}$ panel at $25^{\circ} \mathrm{C}$ are given as $\mathrm{P}_{\mathrm{MPP}}=250 \mathrm{~W}$, IMPP $=8.3$ $\mathrm{A}$ and $\mathrm{V}_{\mathrm{MPP}}=30.1 \mathrm{~V}$. The PV system considers of two strings, each string having two modules in series. The system layout and module characteristics are shown in Fig. 3 (a) \& (b) respectively.

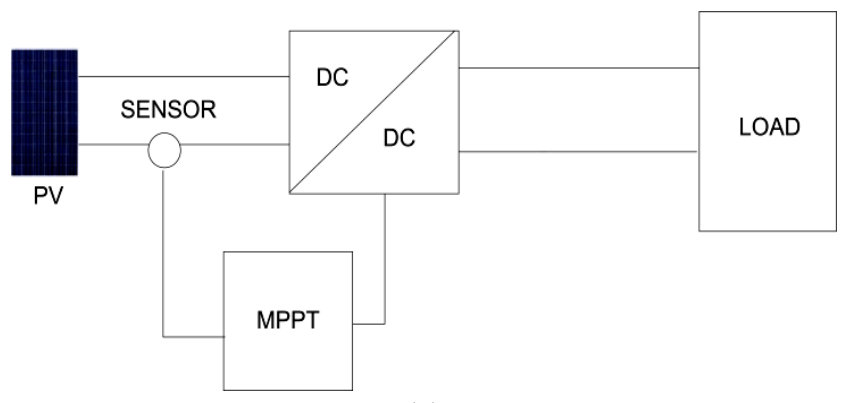

(a)
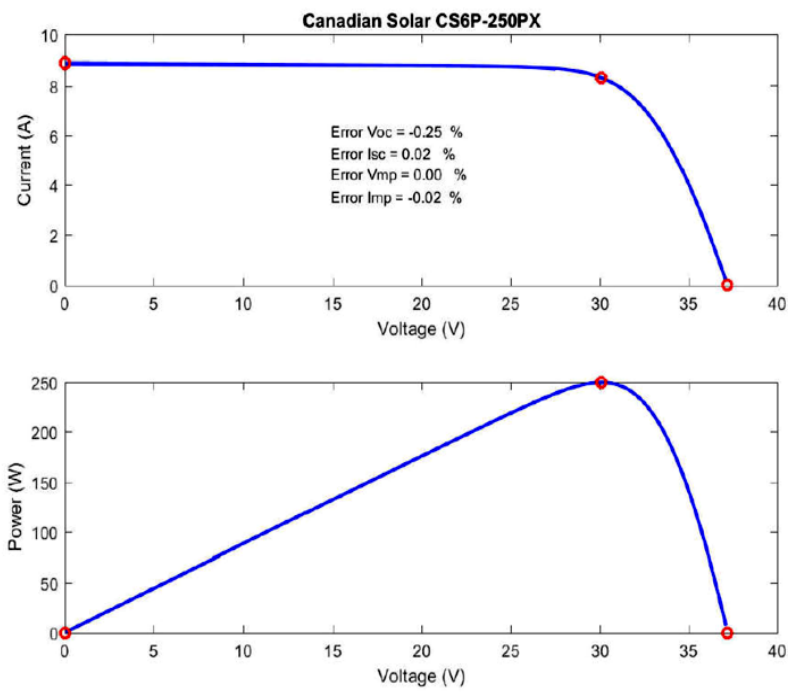

(b)

Fig. 3: (a) System layout (b) P-V and I-V curve of PV module.

\subsection{Simulation analysis}

The designed PV system is simulated with two MPPT control algorithms (P\&O \& MP\&O) individually. Simple P\&O MPPT algorithm based system simulated under constant and RRC conditions and same conditions are also applied to test the MP\&O MPPT algorithm. Radiation and weather data input is considered from Ministry of New and Renewable Energy website of New Delhi, India location.

\subsubsection{Simulation with P\&O MPPT}

During the simulation, it is assumed that the operating temperature is $25^{\circ} \mathrm{C}$. Simulation model and Input radiation curve are shown in Fig. 4 (a) \& (b). The measured output power, voltage, and current using $\mathrm{P} \& \mathrm{O}$ and MP\&O MPPT are shown in Fig. 4 (c) \& (d). The radiation input data given to the solar PV system shows that in initial phase the radiation is constant $900 \mathrm{~W} / \mathrm{m}^{2}$ up to 3 seconds there after it is changing according to ramp and then unit step upto 10 seconds. The PV voltage is constant (60 Volts) with less oscillations but PV current varied according to input radiation value also having high oscillations during simulation. When the radiation gets saturated, the PV power and voltage still have oscillations in the range of 840 to 910 Watt \& 58 to 60 volts respectively as shown in Fig. 4(c). It is observed that the photovoltaic voltage, current, and power have high steady and transient oscillations.

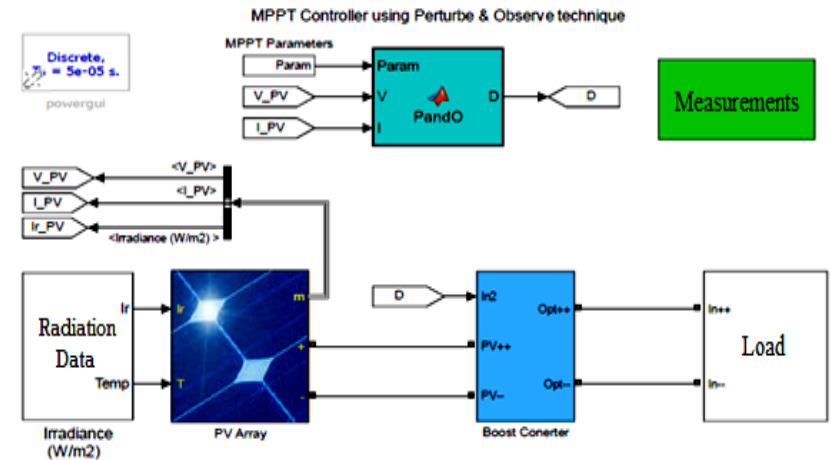

(a)

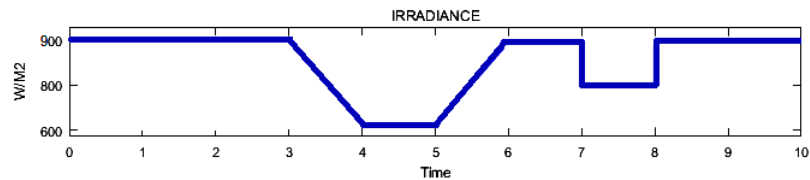

(b)
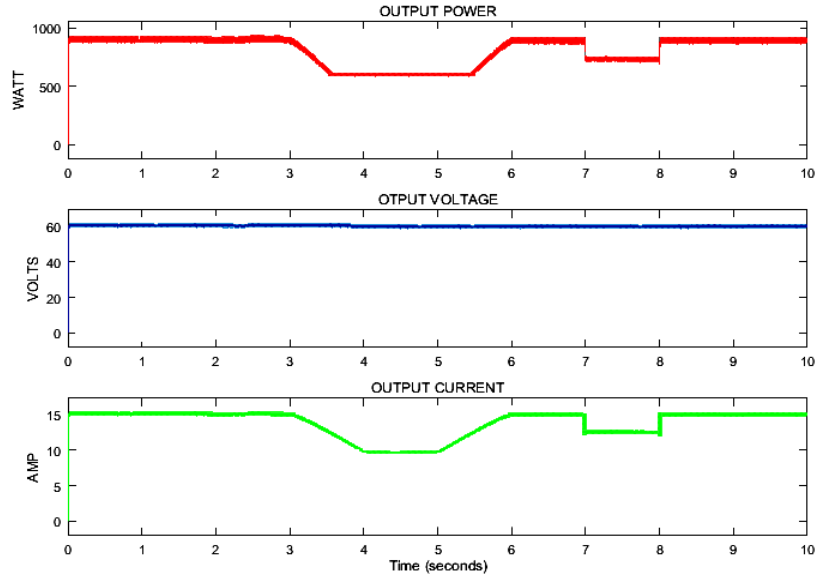

(c)
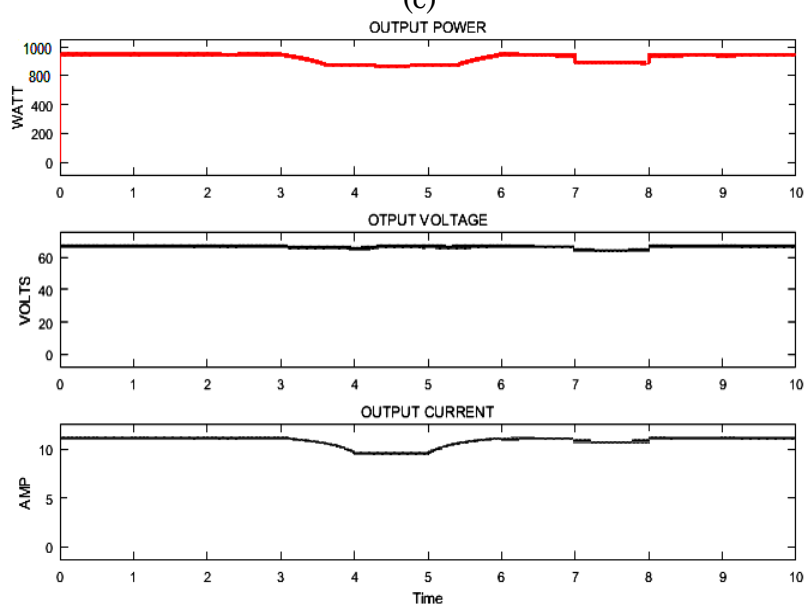

(d)

Fig. 4: (a) Simulink PV model (b) Input radiation pattern (c) Output power, voltage and current using P\&O MPPT (d) Output power, voltage and current using MP\&O MPPT. 
4.2.2. Simulation with modified $P \& O$ (MP\&O) $M P P T$ technique

The MP\&O MPPT technique increases or decreases the value of $\mathrm{dD}$ according to input radiation conditions. MP\&O algorithm, complete MATLAB/Simulink model are described in Fig. 3 \& 4(a). For the same input conditions as above, the output of both MP\&O and P\&O MPPT algorithms are shown in Fig. 4 (d). It is also observed that as the radiation decreases or increases the output voltage is found constant and output current decreases or increases according to radiation data. During 3 to 8 seconds, the output voltage and current have fewer oscillations as compared to conventional P\&O MPPT algorithm as shown in Fig. 4. The output power, current, and voltage are found stable during simulation with MP\&O MPPT technique. Under the transient conditions, the power fluctuations are reduced and the system response is fast.

\subsubsection{Performance evaluation under Rapid Radiation Change Conditions (RRC) with MP\&OMPPT}

The performance of $\mathrm{P} \& \mathrm{O}$ and MP\&O MPPT algorithm is also evaluated under rapid radiation change conditions. The test solar radiation is varied in step and impulse type of sequence for the duration of 10 seconds as illustrated in Fig. 5 (a). The output power, voltage and current of a photovoltaic system with P\&O MPPT and MP\&O MPPT control algorithm under the defined radiation conditions are shown in Fig. 5 (b) \&(c). During the transient and steady state conditions, the MP\&O MPPT has fewer oscillations in the output voltage and current as compared to the $\mathrm{P} \& \mathrm{O}$ algorithm. It is observed that during the rising phase of radiation, the algorithm acts a bit faster. Also, the output power has lesser oscillations as compared to falling radiation conditions.

\subsubsection{Performance under variable load condition}

Under variable load condition the load associated with PV system is varied according to time as described in Fig. 6(a). In the duration of 3 to $5 \mathrm{sec}$, the load is stepped down from $1 \mathrm{~kW}$ to $400 \mathrm{~W}$ and after $5 \mathrm{sec}$ it is retained back to its maximum value. The output voltage is found stable; however, the output current decreases according to load during this period of time. The output current and voltage are found stable during transient as well as steady state conditions which are basic requirement of a PV system as shown in Fig. 6(b).

\section{Experimental Validation}

The photovoltaic system model operation with the MP\&O MPPT algorithm is also experimentally verified. The developed PV system consists a power electronic converter, a chroma Solar Array Simulator $62000 H-S$ which considers two stings each with two PV modules connected in series. The classical boost converter is implemented using new generation SiC Mosfet CAS300M12BM2 based module. The proposed MPPT algorithm is implemented using the dSPACE 1104 controller and a TMS320F240 digital signal processor. dSPACE controller is also used to generate the PWM pulses for SiC Mosfet based boost converter. The same radiation pattern as shown in Fig. 5 (b) taken as input of $\mathrm{PV}$ simulator. The radiation level changes from 0 to $1000 \mathrm{~W} / \mathrm{m}^{2}$ in $3 \mathrm{~s}$ after then the radiation level is saturated at $1000 \mathrm{~W} / \mathrm{m}^{2}$ up-to $8 \mathrm{~s}$. Then after, the radiation level ramps down.

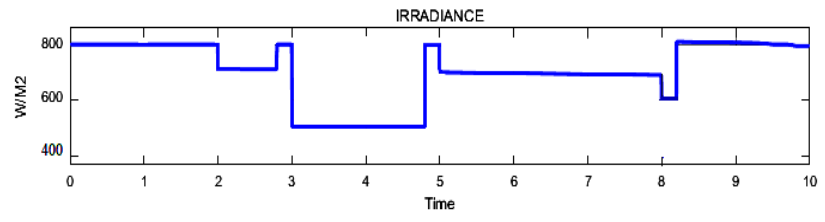

(a)
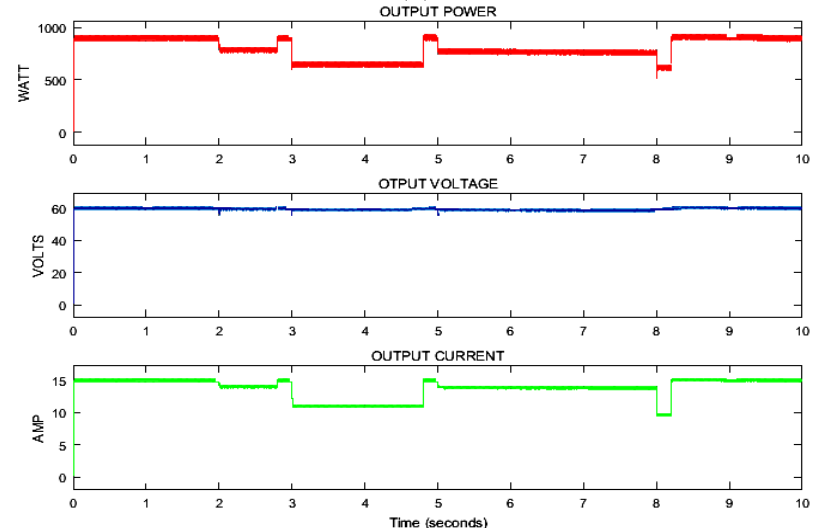

(b)
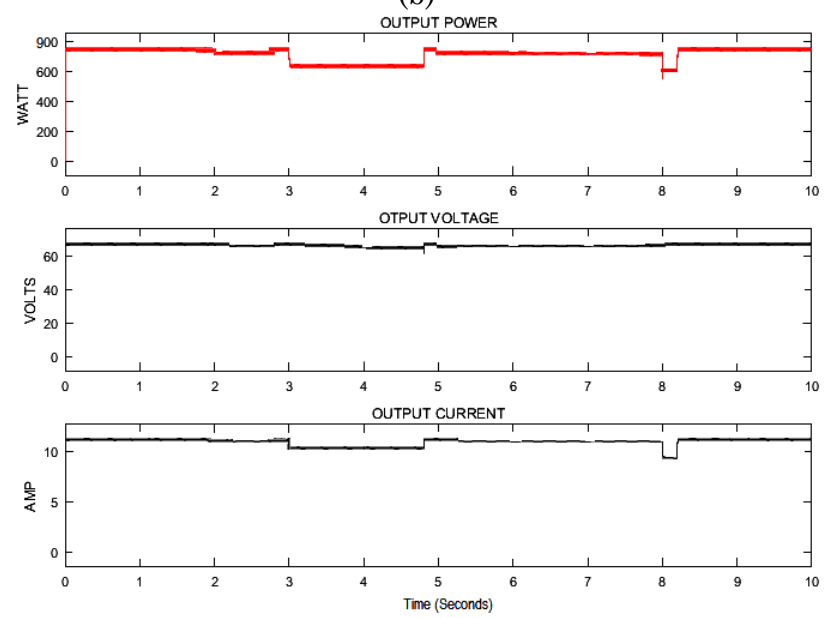

(c)

Fig.5: (a) Fluctuating radiation pattern (b) Output power, voltage and current using P\&O MPPT (c) Output power, voltage and current using MP\&O MPPT technique.

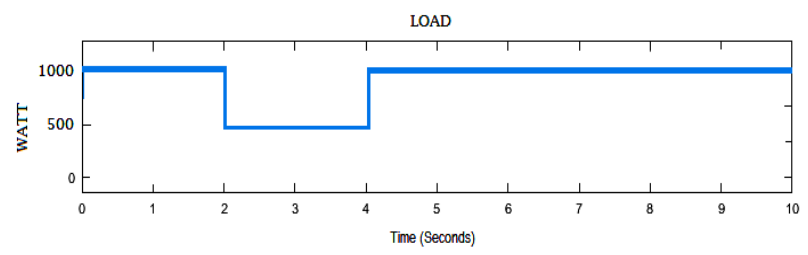

(a)
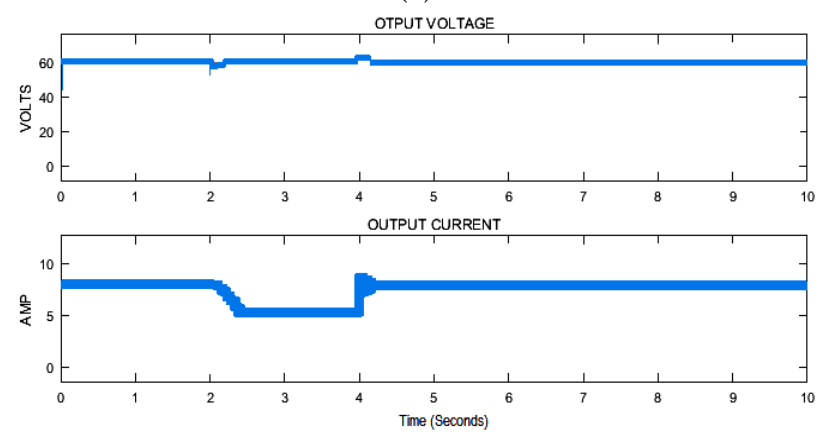

(b)

Fig.6: (a) Variable Load Condition (b) Output Voltage and Current under Variable Load condition. 
The output powers, voltage, current and switching signal for this transition sequence are shown in Fig. 7 (a). It is observed that the system is stable in steady state. The boost converter has a fast-transient response, reaches the MPP in $150 \mathrm{~ms}$ as seen in Fig. 7(b). It is also seen that proposed control system predicts and tracks MPP very fast; in steady state, the oscillations are minimized. Thus, the efficiency of the algorithm is high.

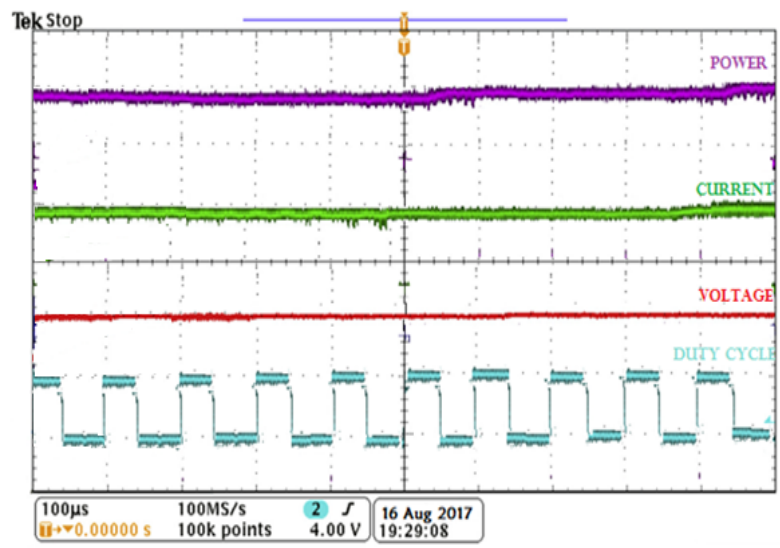

(a)

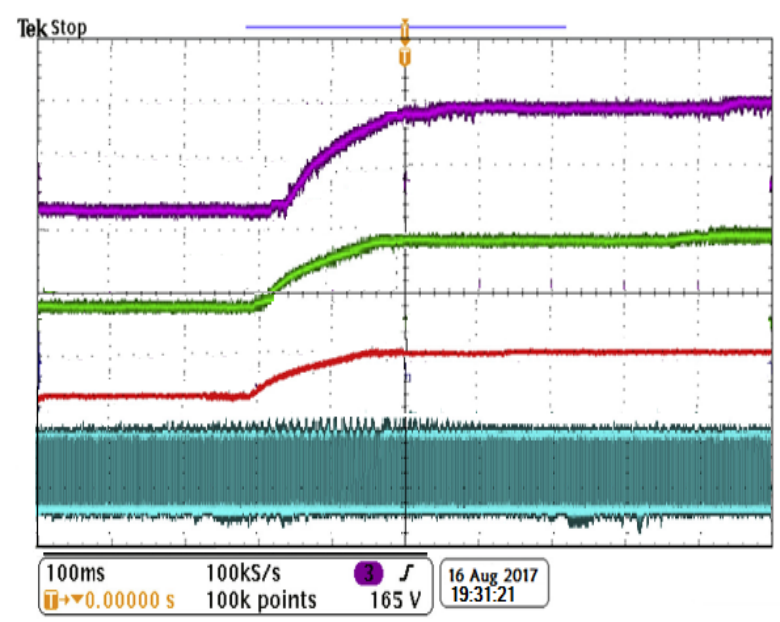

(b)

Fig.7. (a) Output power, voltage, current and duty cycle of experimental setup under uniform radiation. (b) Output power, voltage, current, and duty cycle of experimental Setup under step increasing radiation.

\section{Conclusion}

In this research work, an MP\&O MPPT algorithm is developed with the capability to minimize voltage oscillations around MPP in transient as well as steady state condition and stabilize the output voltage during RRC and variable load conditions particularly for small or residential PV systems. The proposed algorithm is validated on a $1 \mathrm{~kW}$ photovoltaic system, and its performance is investigated under various insolation patterns. The tracking speed of the algorithm is significantly fast as compared to a conventional P\&O method and also incorporates all the advantages and features of other complex algorithms which require highcost converter controllers. Due to the simplicity of this algorithm, it can be easily implemented using a low-cost microcontroller making it versatile, inexpensive and affordable to middle class consumers.

\section{References}

Abdelsalam, A. K. Massoud, A. M. Ahmed, S. and Enjeti, P. M. (2011) High-performance adaptive perturb and observe MPPT technique for photovoltaic-based microgrids. IEEE Transaction on Power Electronics, 26(4), 1010-102.

Agorreta, J. L. Borrega, M. Lo, X. Pez, J and Marroyo, L. (2011) Modeling and control of $N$-paralleled grid-connected inverters with LCL filter coupled due to grid impedance in PV plants. IEEE Transaction on Power Electronics, 26(3), 770-785.

Alajmi, B. N. Ahmed, K. N. Finney, S. J and Williams, B. W. (2011) Fuzzylogic- control approach of a modified hill-climbing method for maximum power point in microgrid standalone photovoltaic system. IEEE Transaction on Power Electronics, 26(4), 1022-1030.

Athira, B. Greeshma, V. Johnson, J. (2016) Analysis of Different MPPT Techniques. International Journal of Advanced Research in Electrical Electronics and Instrumentation Engineering, 5(3).

Bangyin, L. Shanxu, D. and Tao, C. (2011) Photovoltaic DCbuilding-module based BIPV system-concept and design considerations. IEEE Transaction on Power Electronics, 26(5),1418-1429.

Bo, Y. Wuhua, L. Yi, Z. And Xiangning, H. (2010) Design and analysis of a grid connected photovoltaic power system. IEEE Transaction on Power Electronics, 25(4), 992-1000.

Esram, T. And Chapman, P. L. (2007) Comparison of Photovoltaic Array Maximum Power Point Tracking Techniques. IEEE Transaction on Energy Conversion, .22(2) 439-449.

Faranda, R. And Leva, S. (2008) Energy comparison of MPPT techniques for PV Systems. WSEAS Transaction on Power Systems, 13(6), 446-455.

Fatahbadi, H. (2017) A Novel Fast and High accuracy Maximum Power Point Tracking Methode for Hybrid Photovoltaic/Fuel Cell Energy Conversion Systems. Renewable Energy, Elsevier, 106, 232-242.

Femia, N. Petrone, G. Spagnuolo, G. And Vitelli, M. (2005) Optimization of perturb and observe maximum power point tracking method. IEEE Transaction on Power Electronics, 20(4), 963-973.

Hohm, D. P. And Ropp, M. E. (2000) Comparative Study of Maximum Power Point Tracking Algorithms Using an Experimental, Programmable, Maximum Power Point Tracking Test Bed. Proceeding of Photovoltaic Specialist Conference, 1699-1702.

https://rredc.nrel.gov/solar/old_data/nsrdb/

Hua, C. And Shen, C. (1998) Comparative Study of Peak Power Tracking Techniques for Solar Storage System. Proceeding of APEC, 679-685.

Hussein, K. H. Muta, I. Hoshino, T and Osakada, M. (1995) Maximum Power Point Tracking: an Algorithm for Rapidly Chancing Atmospheric Conditions. IEEE Proceeding of Generation Transmission and Distribution, 142(1), 59-64.

Ishaque, K. Salam, Z. And Taheri, H. (2011) Simple, fast and accurate two diode model for photovoltaic modules. Solar Energy Materials. Solar Cells, 95, 586-594.

Ji, Y. H. Jung, D. Y. Jun-Gu. Kim, J. G. Kim, J. H. Lee, T. W. and Won, C. Y. (2011) A real maximum power point tracking method for mismatching compensation in PV array under partially shaded conditions. IEEE Transaction on Power Electronics, 26(4), 1001-1009.

Lee, J. H. Bae, H. and Cho, B. H. (2006) Advanced incremental conductance MPPT algorithm with a variable step size. in: Proceedings of 12th International Power Electronics and Motion Control Conference EPE-PEMC.

Li, Z. Kai, S. Yan, X. Lanlan, F and Hongjuan, G. (2011) A modular gridconnected photovoltaic generation system based on DC bus. IEEE Transaction on Power Electronics, 26(2), 523531.

Liu, B. Duan, S. Liu, F. And Xu, P. (2007) Analysis and improvement of maximum power point tracking algorithm based on incremental conductance method for photovoltaic 
array. In Proceedings of the 7th International Conference on Power Electronics and Drive Systems, PEDS'07.

Liu, F. Kang, Y. Zhang, Y. And Daun, S. (2008) Comparison of P $\& \mathrm{O}$ and hill climbing MPPT methods for grid connected PV converter. in: Proceedings of the 3rd IEEE Conference on Industrial Electronics and Applications, ICIEA.

Liu, F. Daun, S. Liu, F. Liu, B. And Kang, Y. (2011) A variable step size INC MPPT method for PV systems. IEEE Transaction on Industrial. Electronics. 55 (7), 2622- 2632.

Masoum, M. A. Dehbonei, H. and Fuchs, E. F. (2002) Theoretical and experimental analyses of photovoltaic systems with voltage and current-based maximum power point tracking. IEEE Power Engineering, 22(8), 62-72.

Mei, Q. et al. (2011) A novel improved variable step-size incremental-resistance MPPT method for PV systems. IEEE Transaction on Industrial Electronics, 58 (6) 2427 2433.

Mutoh, N. Ohno, M. Inoue, T. (2006) A method for MPPT control while searching for parameters corresponding to weather conditions for PV generation systems. IEEE Transaction On Industrial. Electronics, 53 (4), 1055-1065.

Noguchi, T. Togashi, S. and Nakamoto, R. (2002) Short-current pulse-based maximum-power-point tracking method for multiple photovoltaic-and converter module system. IEEE Transaction on Industrial Electronics, 49(1), 217-223.

Patel, H. and Agarwal, V. (2008) Maximum power point tracking scheme for PV systems operating under partially shaded conditions. IEEE Transaction on Industrial Electronics, 55(4), 1689-1698.

Rai, A. K. Kaushika, N. D. Singh, B. And Agarwal, N. (2011) Simulation model of ANN based maximum power point tracking controller for solar PV system. Solar Energy Mater, Solar Cells, 95, 773-778.

Safari, A and Mekhilef, S. (2011) Simulation and hardware implementation of incremental conductance MPPT with direct control method using cuk converter. IEEE Transaction on Industrial Electronics, 58(4), 1154-1161.

Safari, A. Mekhilef, H. (2011) Simulation and hardware implementation of incremental conductance MPPT with direct control method using Cuk converter. IEEE Transaction on Industrial. Electronics, 58 (4).

Salas, V. Olias, E. Barrado, A and Lazaro, A. (2006) Review of the maximum power point tracking algorithms for stand-alone photovoltaic systems. Solar Energy Materials and Solar Cells,.90,1555-1578.

Sera, D. Teodorescu, R. Hantschel, J. and Knoll, M. (2008) Optimized maximum power point tracker for fastchanging environmental conditions. IEEE Transaction on Industrial Electronics, 55(7), 2629-2637

Serban, E. And Serban, H. (2010) A control strategy for a distributed power generation microgrid application with voltage- and current-controlled source converter. IEEE Transaction on Power Electronics, 25(12), 2981-2992.

Tey, K. S. And Mekhilef, S. (2014) Modified incremental conductance MPPT algorithm to mitigate inaccurate responses under fast-changing solar irradiation level. Solar Energy, Elsevier, 101, 333-342.

Tey, K. S. And Mekhilef, S. (2014) Modified incremental conductance algorithm for photovoltaic system under partial shading conditions and load variation. IEEE Transaction on Industrial Electronics, 61(10), 5385-5392.

Xiao, W and Dunford, W. G. (2004) A modified adaptive hill climbing MPPT method for photovoltaic power systems. in: Proceedings of IEEE 35th Annual Power Electronics Specialists Conference, PESC 04.

Yan, Z. Fei, L. Jinjun, Y. and Shanxu, D. (2008) Study on realizing MPPT by improved incremental conductance method with variable step-size. In Proceedings of the 3rd IEEE Conference on Industrial Electronics and Applications. 